\title{
Successful biliary cannulation using a novel rotatable sphincterotome in a patient with situs inversus totalis
}

Situs inversus totalis (SIT) is a rare congenital deformity involving complete transposition of all of the viscera. Endoscopic retrograde cholangiopancreatography $(E R C P)$ is challenging in patients with SIT owing to anatomical anomalies [1]. Here we present the case of a patient with SIT who successfully underwent biliary cannulation by ERCP using a novel rotatable sphincterotome.

An 83-year-old woman with obstructive jaundice due to advanced gallbladder cancer was referred to our hospital. Abdominal computed tomography showed transposition of the liver and gallbladder to the left upper quadrant and distal biliary obstruction owing to lymph node metastasis (> Fig. 1).

ERCP was performed with the patient in the usual prone position; the endoscopist was on the left side of the table. The duodenoscope was advanced into the second portion of the duodenum, and the papilla was oriented to the right at the 1-o'clock position ( $\mathbf{F i g} \cdot \mathbf{2}$ ). Biliary cannulation was attempted using a conventional ERCP catheter but was unsuccessful. To adjust the biliary axis, a novel rotatable sphincterotome (TRUEtome, Boston Scientific, Marlborough, Massachusetts, USA) was used. The TRUEtome is a sphincterotomy device that allows vertical and horizontal rotation of the tip (> Fig.3). Biliary cannulation was successfully achieved by moving the catheter tip to adjust the biliary axis ( $\mathbf{F i g . 4 ;}$ - Video 1). Following biliary cannulation, endoscopic sphincterotomy was performed using the TRUEtome, and a selfexpandable metal stent (ZEOSTENT Plus; Zeon Corporation, Tokyo, Japan) was deployed to cover the biliary stricture ( $\vee$ Fig.5). No procedure-related adverse events were noted, and the patient's jaundice resolved within a few days.

There have been reports of successful ERCP in patients with SIT by making a
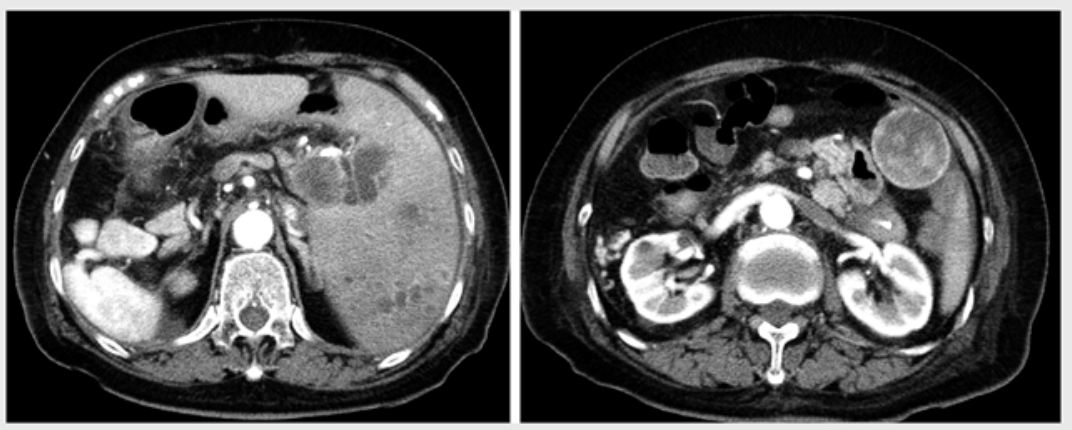

- Fig. 1 Abdominal contrast-enhanced computed tomography scan showing transposition of the liver and gallbladder to the left upper quadrant and distal biliary obstruction due to lymph node metastasis.

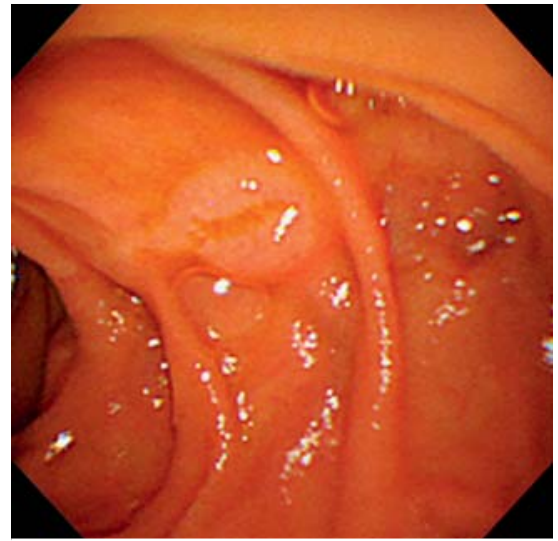

-Fig. 2 Endoscopic view from the second portion of the duodenum showing the papilla oriented to the right at the 1-o'clock position.

change in the patient position or the endoscope insertion location [2-4]. The present case indicates that a rotatable sphincterotome is a useful device that enables biliary cannulation in patients with SIT by vertically and horizontally adjusting the catheter tip with the patient in the conventional position and the usual scope insertion location.

Endoscopy_UCTN_Code_TTT_1AR_2AB

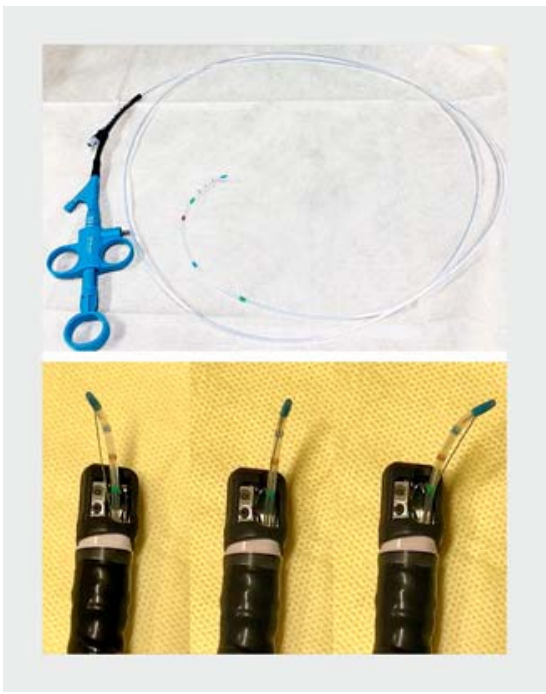

- Fig. 3 The TRUEtome is a sphincterotomy device that allows rotation of the tip both vertically and horizontally, thereby ensuring optimal orientation for the biliary axis.

\section{Competing interests}

The authors declare that they have no conflict of interest. 

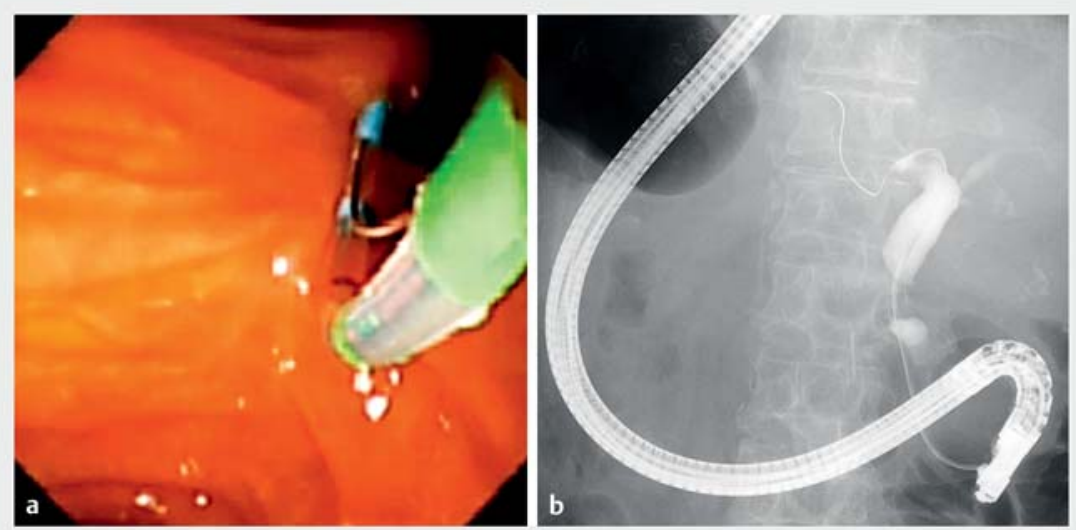

- Fig. 4 Biliary cannulation was successfully achieved by adjusting the axis with movement of the tip of the catheter vertically and horizontally, as shown on: a endoscopic view; b fluoroscopic view.

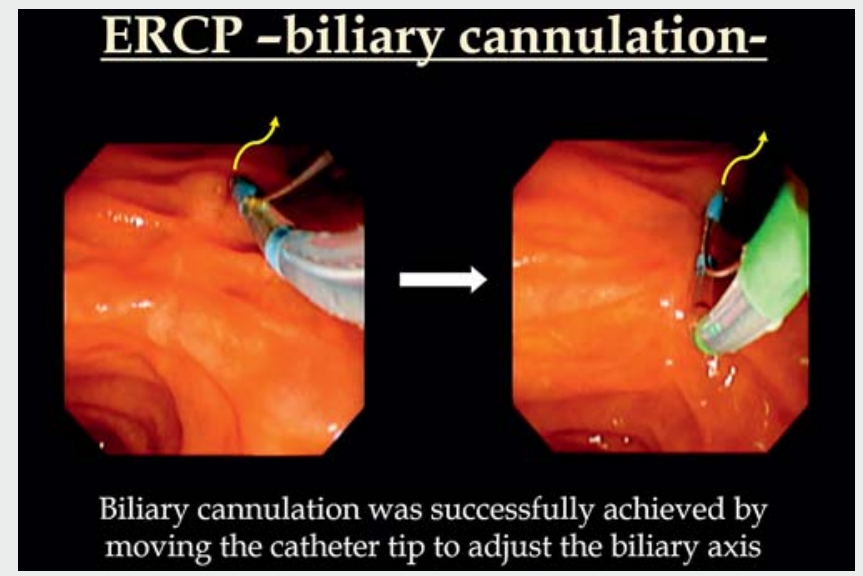

Video 1 Successful biliary cannulation by endoscopic retrograde cholangiopancreatography using a novel rotatable sphincterotome in a patient with situs inversus totalis.
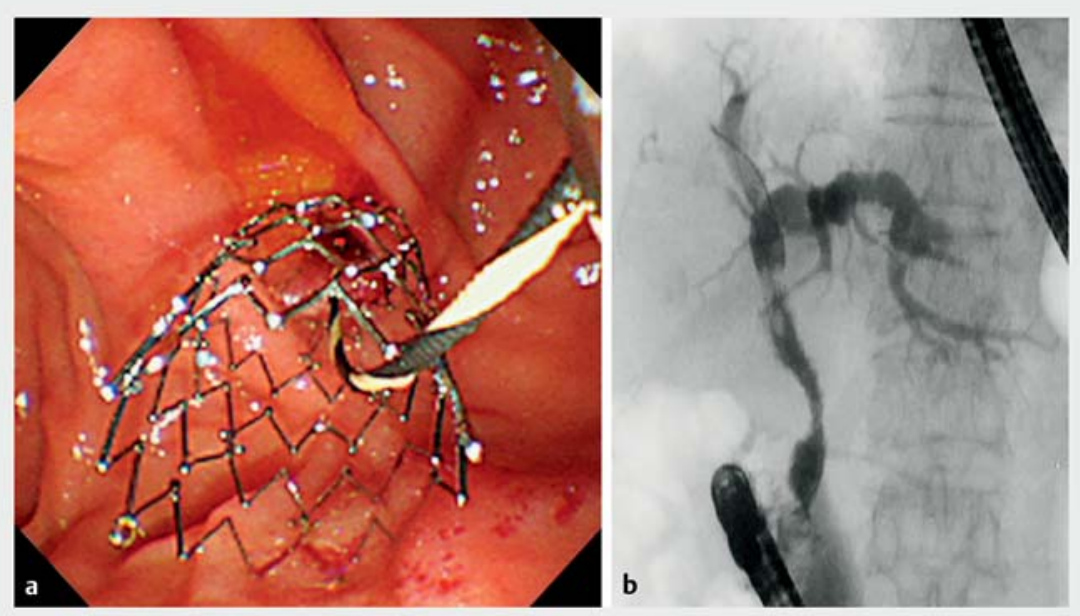

- Fig. 5 A self-expandable metal stent was deployed to cover the distal biliary stricture, as seen on: a endoscopic view; b fluoroscopic view.
The authors

Akihiro Yoshida ${ }^{1,2}$, Kosuke Minaga ${ }^{1}$, Osami Takeda $^{2}$, Hajime Hanno ${ }^{2}$, Shigenori

Takayanagi ${ }^{2}$, Toshio Dozaiku², Masatoshi Kudo ${ }^{1}$

1 Department of Gastroenterology and Hepatology, Kindai University Faculty of Medicine, Osaka-Sayama, Japan

2 Department of Gastroenterology, Fuchu Hospital, Izumi, Japan

\section{Corresponding author}

\section{Akihiro Yoshida, MD}

Department of Gastroenterology and Hepatology, Kindai University Faculty of Medicine, 377-2 Ohno-Higashi, OsakaSayama, 589-8511, Japan

Fax: +81-72-3672880

ackiy0409@gmail.com

\section{References}

[1] Venu RP, Geenen JE, Hogan W] et al. ERCP and endoscopic sphincterotomy in patients with situs inversus. Gastrointest Endosc 1985; 31: 338-340

[2] Nordback I, Airo I. ERCP and endoscopic papillotomy in complete abdominal situs inversus. Gastrointest Endosc 1988; 34: 150

[3] Fiocca F, Donatelli G, Ceci V et al. ERCP in total situs viscerum inversus. Case Rep Gastroenterol 2008; 2: 116-120

[4] Hu Y, Zeng H, Pan XL et al. Therapeutic endoscopic retrograde cholangiopancreatography in a patient with situs inversus viscerum. World J Gastroenterol 2015; 21: 5744-5748

\section{Bibliography}

DOI https://doi.org/10.1055/a-1122-8416

Published online: 4.3.2020

Endoscopy 2020; 52: E333-E334

(c) Georg Thieme Verlag KG

Stuttgart · New York

ISSN 0013-726X 